\title{
A rare case of urocolpos
}

\section{Suvarna Jyothi Ganta ${ }^{1}$, Sunanda Kulkarni ${ }^{1}$, Ninan Thomas ${ }^{2}$}

\author{
${ }^{1}$ Department of Obstetrics and Gynaecology, Chinmaya Mission Hospital, Bangalore, Karnataka, India \\ ${ }^{2}$ Department of Urology, Chinmaya Mission Hospital, Bangalore, Karnataka, India
}

Received: 12 February 2016

Revised: 24 April 2016

Accepted: 07 May 2016

\section{*Correspondence:}

Dr. Suvarna Jyothi Ganta,

E-mail: Suvarnajyothi0705@gmail.com

Copyright: () the author(s), publisher and licensee Medip Academy. This is an open-access article distributed under the terms of the Creative Commons Attribution Non-Commercial License, which permits unrestricted non-commercial use, distribution, and reproduction in any medium, provided the original work is properly cited.

\begin{abstract}
Urocolpos (uro-urine, Colpos-vagina) is distension of the vagina due to the accumulation of urine; it is a rare occurrence.it can be seen from young pre-pubertal girls to post-menopausal women. Labia minora adhesions can be partial or complete.in pre-pubertal girls the fusion caused due to hypoestrogenic state may be asymptomatic and present only as urinary retention. It can be mistaken for haematocoplos, which should be ruled out. We present a case report of a young female patient who presented with complete labial fusion with urocolpos with urinary incontinence. She was surgically treated and is being followed up with no recurrence.
\end{abstract}

Keywords: Puberty, Labial fusion, Adhesions, Urinary tract infection, Urinary retention, Urocolpos

\section{INTRODUCTION}

Urocolpos is rare entity. It is seen from young girls to old ladies. It may be mistaken for hematocolpos some times. The case is reported because of its rarity. Urocolpos in mainly due to labial adhesion. Labial fusion may be partial or complete. When complete it encloses urethra leading to urocolpos. Can be seen in all age group due to different etiology. The incidence of labial adhesions is more frequent in young prepubertal girls aged 3 months to 6 years with a peak incidence at 13-23 months of age. Labia minora adhesions (LMA) are a common finding in young girls. Usually, this condition is asymptomatic and spontaneously disappears during adolescence. ${ }^{1}$ Prepubertal girls with labial adhesions may be asymptomatic or may present with symptoms like urinary retention, painful voiding of urine and thin stream, with post-void dripping (urinary incontinence), urinary tract infections, vaginitis (vaginal irritation), haematuria and urinary frequency. Vaginal irritation, hypoestrogenism, local trauma, lack of sexual activity, female circumcision, vaginal lacerations in childbirth and recurrent urinary tract infections causing vaginal inflammation are formerly reported as the contributing factors for Labial
Fusion in adults. ${ }^{2}$ Topical estrogen application is the treatment for superficial labial adhesions.

\section{CASE REPORT}

A 21 year old unmarried girl was admitted in the hospital with complaints of fever for 2 days, burning micturition and pain lower abdomen since one week. She also complained of continuous dribbling of urine for the past 6 months. She had fever which was high grade associated with chills. The pain in the lower abdomen was an aching sensation, non-colicky, non-radiating associated with increased frequency and dysuria. She did not give any history of haematuria, white discharge, pruritus, injury or sexual assault or circumcision. Her cycles were regular with moderate flow. There was no dysmenorrhea.

On examination, her all vital parameters were normal. There was no organomegaly .Local examination revealed fusion of labia majora which was almost complete (Figure 1). Clitoris was visible, a small opening of $0.5 \mathrm{X}$ $0.5 \mathrm{~cm}$ noted in the midline from where there was dribbling of urine. There were depigmented patches over the fused labia. Per rectal examination revealed bulging 
colpos. A provisional diagnosis of haematocolpos was made.

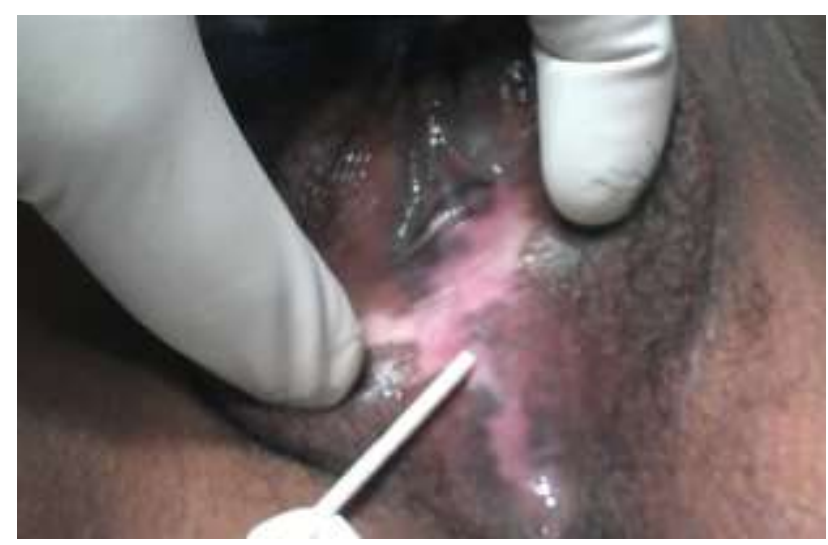

Figure 1: Pre-operative image of labial fusion.

Labial fusion: The labia majora are completely fused, leaving a very small opening to allow urination; a probe is inserted to show the pin-hole opening.

Ultrasound scan showed a distended vagina with fluid collection in the vagina. Uterus was anteverted, of normal size and ovaries were normal. Laboratory report showed plenty of pus cells in the urine and other parameters were normal.

Under general anesthesia, in lithotomy position, through the small opening a cystoscope was inserted and vagina was visualized behind the fused labia, labial adhesion was dissected with sharp dissection the labia were separated and the released edges were sutured (Figure 2). Intraoperative visualization confirmed that cervix and vagina were anatomically normal. And urine was drained from the distended vagina, bladder was easily catheterized She was advised to use estrogen cream. The patient was discharged with daily topical estrogen ointment therapy to be applied for four weeks. On her postoperative follow up at the end of six weeks, labial tissues were found to be completely healed.

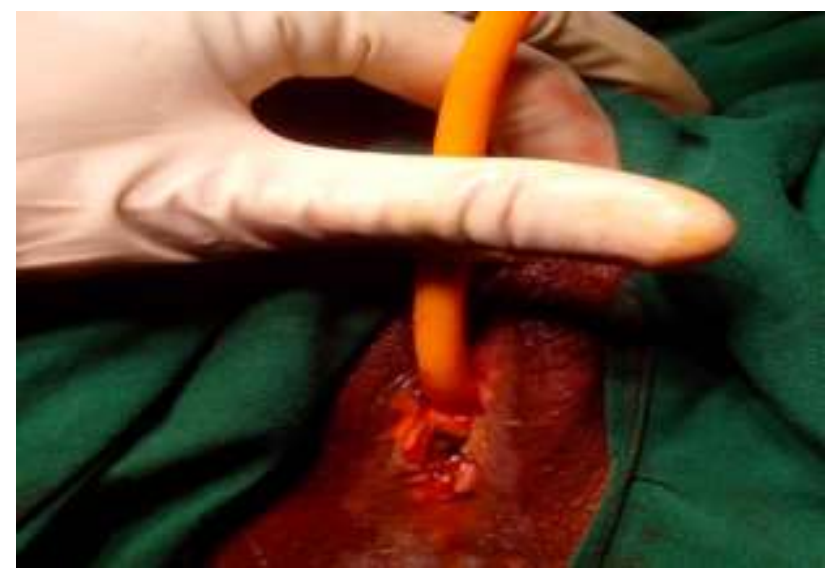

Figure 2: Post-operative appearance of the labia majora.
Dissected labia majora: Post-operative appearance of the labia after the dissection and separation.

\section{DISCUSSION}

In the present case there was almost complete labial fusion except a small opening through which urine was dribbling. She used to have menstruation also through the same opening. She had dribbling of urine when the colpos was full. As the fusion progressed she developed dribbling slowly. Most of the time stasis of urine leads to urinary tract infection. There are cases where this has led to even peritonitis. Constant dribbling of urine may lead to itching, soreness, burning. Some may notice nocturnal enuresis.

Labial adhesions after puberty are rare and usually the result of chronic inflammation, urinary tract infection, hypoestrogenism or surgical procedures leading to vulval trauma. During labial trauma, denuding of the upper squamous epithelial layer of labial mucosa leads to formation of connective Tissue Bridge between the healing labia due to vulvovaginits and poor local hygiene. It is seen in childhood especially in pre pubertal girls where there is relatively estrogen deficiency, again in post-menopausal age for the same reason or due to lichen planus, lichen sclerosis etc. There are many reasons for labial adhesions like Bachet's syndrome, female circumcision, toxic epidermal necrolysis, vulval carcinoma, etc. Rarely ectopic ureter opening in the vagina may also lead to urocolpos. Differentiating point from hematocolpos are absence of mass per abdomen (excludes hematometra) and bluish discoloration of the hymen. Postpartum labial fusion is a rare phenomenon for a woman with no evidence of hypo-estrogenism but cases have been reported in literature. ${ }^{4}$

In young pubertal girls, history of genital trauma and sexual abuse can also lead to partial or complete vulvar fusion. $^{5,7}$ In postmenopausal woman complete labial fusion will present with recurrent urinary tract infection, retention and incontinence. ${ }^{6,8}$ Adhesions of the labia are extremely rare in the reproductive population with only a few cases described in the literature, if present may cause coital and voiding difficulty. ${ }^{2,9}$ Post-menopausal woman with adnexal mass and abdominal pain due to fusion of the labia majora which was diagnosed as a pyosalpinx secondary to long standing urocolpos has been recorded in literature. ${ }^{10}$

Adequate exogenous estrogens in these patients would change the vaginal epithelium from the thin atrophic one to a thick one containing glycogen and the $\mathrm{pH}$ of the vaginal secretions would prevent inflammation and infection. Topical estrogen cream is generally accepted as the initial therapy for superficial labial adhesions which may reduce the irritation of the vaginal mucous membranes and ease subsequent repair particularly in prepubertal girls and postmenopausal women. ${ }^{11}$ One study comparing topical estrogen and betamethasone 
treatment for the treatment of Labial fusion in prepubertal girls noted that betamethasone therapy was superior to topical estrogen therapy in terms of efficacy, recurrence and side effects. Surgery should become the first option for treatment, in patients with complete, thick adhesions and a long history of LF. Our patient's age, status and the subsequent complications if left untreated made us choose surgery instead of topical therapy.

Patients with thin adhesions can be treated with topical estrogens but patients with dense fibrous adhesions and recurrence in patients who have undergone surgical separations of the labia are less likely to respond to topical estrogen therapy alone. In cases that recur after surgical incision of adhesions amniotic membrane covering after surgical incision has been proposed. Fused labia can be separated by scissors, or can be stretched by fingers also. Surgery is required only when there is no response to estrogen cream, or if the adhesions are thick.

Funding: No funding sources

Conflict of interest: None declared

Ethical approval: Not required

\section{REFERENCES}

1. Centeno-wolf N, Chardot C, Le Coultre CP, La Scala GC. Infected urocolpos and generalized peritonitis secondary to labia minora adhesions. J Pediatr Surg. 2008;43(9):e35-9.

2. Ozekinci M, Yucel S, Sanhal C, Akbar M. labial fusion causing coital and voiding difficulty in young woman. Advances in sexual medicine.2013;3(1):113.
3. Mayaoglu L, Dulabon L, Algucil MN, Pfaff D. Success of treatment modalities for labial fusion: A Retrospective Evaluation of Topical and Surgical Treatments. Journal of Pediatric and Adolescent Gynaecology. 2009;22(4):247-53.

4. Lambert B. Complete Adult Vulvar Fusion: A case Report. Journal of Obstetrics and Gynaecology Canada. 2004;26(5):501-2.

5. Kumar RK, Sonika A, Charu C, Sunesh K. Labial Adhesions in Pubertal Girls. Archives of Gynaecology and Obstetrics. 2006;273(4):243-5.

6. Muppala H, Meshki A. Voiding Dysfunction Due to Longstanding Labial Fusion in an Elderly Woman: A case Report. International Urogynaecology Journal and Pelvic Floor Dysfunction. 2009;20(2):251-2.

7. Berkowitz CD, Elvik SL, Logan MK. Labial Fusion in Prepubescent Girls: A Marker for Sexual Abuse? American Journal of Obstetrics Gynecology. 1987;156(1):16-20.

8. Dirim A, Hasirci E. Labial Fusion Causing Urinary Incontinence and Recurrent Urinary Tract Infection in a Postmenopausal Female: A case Report. International Urogynaecology Journal. 2011;22(1):119-20.

9. Tsujita Y, Asakuma J, Kanbara T, Yoshii T, Azuma R, Sumitomo M. A Case of Labial Adhesion in a Reproductive Woman. Hinyokika Kiyo. 2010;56(8):463-5.

10. Ortega Mariscal J, Congregado Ruiz B, Campoy Martinez P, Perez Perez M, Rodriguez Perez A, Soltero Gonzalez A. Urinary incontinence caused by urocolpos a case report. Actus urologicas espanolas. 2001;25(6):450-1.

11. Lubsen-Brandsma MA. Adhesions of the labia minora in three young girls. 2003;147(2):53-6.

Cite this article as: Ganta SJ, Kulkarni S, Thomas N. A rare case of urocolpos. Int J Reprod Contracept Obstet Gynecol 2016;5:2034-6. 